JERZY PASZEK

Instytut Nauk o Literaturze Polskiej

Uniwersytet Śląski w Katowicach

\title{
BIBLIOTEKA BLOOMA
}

\author{
Słowa kluczowe: Joyce, Ulisses, motywy przewodnie, Berent
}

Keywords: Joyce, Ulysses, leitmotifs, Berent

Ulysses is both dynamic and static. There must be several thousand recurring motifs, and it would require a volume almost the size of the original to expound all of them.

Richard M. Kain ${ }^{1}$

\section{5 tomów}

W zasadzie należałoby ten ryzykowny esej zatytułować „Biblioteczka Blooma”, bo nawet dodając tomy, znajdujące się pod łóżkiem Molly, ukochanej żony Leopolda (Ruby: chluba areny), w szufladzie biurka (Hagada) i w kieszeni dublińskiego akwizytora (Słodycze grzechu), to i tak będzie tu tylko 25 książek. Nawiasem mówiąc, liczba ta rymuje się z 25 kochankami, których zazdrosny i niespełniony mąż (brak męskiego potomka!) przypisuje pani Marion, z domu Tweedy². Wedle solilokwium Molly (epizod „Penelopa”) ilość ta powinna być

${ }^{1}$ Richard M. Kain, „Motif as Meaning: The Case of Leopold Bloom”, in Approaches to „Ulysses”. Ten Essays, ed. Thomas F. Staley and Bernard Benstock (London: Henry M. Snyder \& Co., Inc., 1970), 86 (tłumaczenie motta: „Ulisses jest zarówno dynamiczny, jak i statyczny. Mamy tu kilka tysięcy powracających motywów, które wymagają wyjaśnień w tomie o wymiarach oryginału”). I rzeczywiście, komentarze badaczy - Dona Gifforda oraz Weldona Thorntona (vide przypis 7 i 14) - przewyższają swą objętością gabaryty powieści!

${ }^{2}$ James Joyce, Ulisses, trans. Maciej Słomczyński (Kraków: Wydawnictwo Zielona Sowa, 1997), 662; katalog książek - ibidem, 637-639; idem, Ulysses (Hardmonsworth, Middlesex, England: Penguin Books, 1968), 652; 629-630. Spór o ilość kochanków Molly trwa od wielu lat, vide David Hayman, „The Empirical Molly” in Approaches to „Ulysses”, 103-135; Darcy O’Brien, „Some Determinants of Molly Bloom", in ibidem, 137-155. Charles H. Peake broni Blooma, wywodząc, iż w jego języku „suitors” to nie są kochankowie Molly, lecz jej admiratorzy (idem, James Joyce. The Citizen and the Artist (Stanford, Cal.: Stanford University Press, 1977), 288. 
drastycznie zmniejszona, bo pierwszą zdradę popełniła w dniu akcji (16 czerwca 1904 roku), czyli tuż przed nocnymi (17 czerwca) zapiskami mocno podejrzliwego i podejrzanego o masochistyczne nastawienie pana Poldiego. I jeśli liczba książek, jak na ambitnego biznesmena i żądnego wiedzy poszukiwacza prawdy przystało, nie wydaje się przesadzona, to już lista potencjalnych - a nic tu nie jest przesądzone - cudzolubów (jak mawiano drzewiej w Polsce, co przypomina Zygmunt Kubiak w swym znakomitym spolszczeniu Eneidy ${ }^{3}$ ), grzeszy koloryzowaniem i hiperbolą!

Biblioteczką Blooma zachwyca się Vladimir Nabokov, stwierdzający, że jest to „cudowny katalog książek”4. Jeśli nawet nie poraża nas liczba tomów w domu akwizytora, to należy dodać, iż biznesmen umie w potrzebie (wyszukanie ozdób drukarskich do ogłoszenia) skorzystać z zasobów Irlandzkiej Biblioteki Narodowej (epizod „Scylla i Charybda”), a w dniu 17 czerwca 1904 roku ma jeszcze na półce egzemplarz wypożyczony z Biblioteki miasta Dublina i przetrzymany 13 dni. Sa to Listy Starka-Munro autorstwa Arthura Conan Doyle'a (nie przełożone jeszcze na język polski; w najnowszej filmowej i zarazem kultowej, jak mawia młodzież, wersji przygód Sherlocka Holmesa z Benedictem Cumberbatchem i Martinem Freemanem, lektor czyta: „na podstawie opowiadania Sir Arthura Conana Doyle'a” - „O, témpora, o mores!”, cytując Cycerona). W oryginale tę 11. pozycję z podręcznego katalogu Blooma zapisano jako: The Stark-Munro Letters by A. Conan Doyle ${ }^{5}$. Słomczyński spolszczył więc pierwszą część nazwiska nadawcy, natomiast - filologiczna ciekawostka! - czeski tłumacz, Aloys Skoumal, odmienia drugą część tegoż: Dopisy Stark Munroa ${ }^{6}$. Znacznie bardziej pasjonujące może być jednak wytropienie pełnego tytułu wypożyczonej przez Blooma powieści, opartej na osobistych przeżyciach autora: The Stark Munro Letters: being a series of sixteen letters written by J. Stark Munro, M.B., to his friend and former fellow-student, Herbert Swanborough, of Lowell, Massachusetts, during the years 1881-1884 (London 1895) 7 .

Nasuwa się pytanie, dlaczego Leopold Bloom nie oddał w terminie owego tomu do miejskiej biblioteki? Sądząc po przytoczonym długaśnym tytule - i etymologii

${ }^{3}$ Publius Vergilius Maro, Eneida, trans. Zygmunt Kubiak (Warszawa: Państwowy Instytut Wydawniczy, 1987), 307, 349 (nb., chodzi o Parysa).

${ }^{4}$ Vladimir Nabokov, Wykłady o literaturze, trans. Zbigniew Batko (Warszawa: Warszawskie Wydawnictwo Literackie MUZA, 2000), 455; idem, Lectures on Literature: Auden, Dickens, Flaubert, Joyce, Proust, Stevenson, ed. Fredson Bowers, Introduction by John Updike (New York and London: Harcourt Brace Jovanovich, Publishers, 1980), 360 (,a wonderful catalogue of his books”).

${ }^{5}$ James Joyce, Ulysses, 629.

${ }^{6}$ James Joyce, Odysseus, trans. Aloys Skoumal (Praha: ARGO, 1993), 471.

${ }^{7}$ Weldon Thornton, Allusions in „Ulisses”. An Annotated List (Chapel Hill: The University of North Carolina Press, 1968) 475. Tłumaczenie tytułu: Listy Starka Munro, będace seria szesnastu listów, pisanych przez J. Starka Munro, kaw. Ord. Imp. Br., w latach 1881-1884 do jego przyjaciela i dawnego kolegi ze studiów, Herberta Swanborougha, mieszkającego w Lowell, Massachusetts. 
nazw własnych - można przypuszczać, iż Joyce zawarł tu aluzję do męskiej przyjaźni, jaka w dniu poprzednim, czyli 16 czerwca 1904 roku, nawiązała się (patrząc stale z perspektywy ojca Milly) między przeciętnym akwizytorem a „profesorem i autorem" (w uniżonej tytulaturze Poldiego) Stefanem Dedalusem. Rzecz ta byłaby zapewne wyjaśniona przez Słomczyńskiego, gdyby zdążył napisać zapowiadany na drugiej stronicy Dziet zebranych Joyce'a (przez Wydawnictwo Zielona Sowa) Stownik zagadek „Ulissesa”. Ten ukryty przed okiem mniej dociekliwego czytelnika pełny tytuł powieści Conan Doyle’a koresponduje z prześmiewczym i prześmiesznym nagłówkiem ostatniej pozycji w omawianym katalogu:

Krótkie lecz Jasno Wyłożone Zasady Jeometrii napisane po francusku przez F. Ignat. Pardiesa i na angyelski przełożone przez Johna Harrisa D.D. Londyn, a drukiem wydane dla R. Knaplocka w Bifhop's Head, MDCCXI, z przefłaniem dedykowanem jego Czcigodnemu Przyjacielowi Coxowi, fzlachetnie urodzonemu, Posłowi do Parlamentu z wolnego miasta Southwark i mające na wolnej kartce wykaligrafowane stwierdzenie, że książka ta była własnością Michaela Gallaghera, datę 10 dnia miesiąca maja 1822 i prośbę do osoby, która by ją odnalazła, gdyby kfiążka ta zagubiła fię lub zoftała gdzie zarzucona, aby przywróciła ją Michaelowi Gallagherowi, ftolarzowi, Dufery Gate, Ennifcorthy, hrabftwo Wicklow, najpiękniejfze miejfce na fwiecie 9

Nie chodzi mi o to, że prawdziwy tytuł tego tłumaczenia brzmiał nieco inaczej, gdyż była to książka wydana w 1711 roku pod nagłówkiem: Short but yet plain Elements of Geometry and Plain Trigometry (sic! $)^{10}$. Joyce nieco skraca sam tytuł: Short but yet Plain Elements of Geometry i zmienia lekko zapis imion autora (F. Ignat. Pardies zamiast autentycznego Ignance'a Gastona Pardiesa ${ }^{11}$ ). Jest więc tak, że mało ważna w zbiorze Blooma książka przedstawiona została w całej barokowej okazałości (zapiski dawniejszego właściciela, przywiązanego nad wszelki wyraz i pojęcie do tego podręcznika!), natomiast pominięto pełny zapis tytułu powieści Conan Doyle’a, mogący rzucić nowe światło na zainteresowania i intencje (w stosunku do nocnego gościa, częstowanego filiżanką kakao ${ }^{12}$ ) Leopolda, męża ponętnej kobiety, diwy, prezentującej się na muzycznych koncertach w całej Irlandii. To jedna $\mathrm{z}$ wielu zagadek, jakie wymyślił Joyce dla dociekliwych i wścibskich badaczy, a dla prostodusznych czytelników - podstawa narzekań na niezrozumiałość tekstu tej encyklopedycznej powieści.

${ }^{8}$ Dufery Gate jest też w oryginale (James Joyce, Ulysses, 630), czyli po polsku czytamy tu o bramie z „duserami” („komplementami”), gdy po angielsku „duffer” oznacza tumana! Tej gry słów Joyce chyba nie planował, choć należy do klasy drugiej (Class 2) pisarzy, czyli tych czułych na anagramy, palindromy czy kalambury, vide Anthony Burgess, Joysprick. An Introduction to the Language of James Joyce (New York and London: Harcourt Brace Jovanovich, Publishers, 1975), 15-16; nb. ibidem, 13-15 - genialne tłumaczenie na prosty język angielski początkowych akapitów tekstu Ulissesa. Fraza „najpiękniejsze miejsce na świecie” jest teraz reklamą hrabstwa Wicklow!

${ }^{9}$ James Joyce, Ulisses, 638-639.

${ }^{10}$ Weldon Thornton, op. cit., 476.

${ }^{11}$ Ibidem. Vide James Joyce, Ulysses, 630. 
Podobną enigmą jest czytana przez Molly powieść Ruby: chluba areny ${ }^{13}$, którą napisała - jak dopiero niedawno odkryto - Amye Reade (Thornton jeszcze powątpiewał w autentyczność tego tytułu i nie znalazł autorki $\left.{ }^{14}\right)$. O technice przywoływania przez Joyce'a obcych tekstów może doskonale (jakaż wpadka Encyklopedysty!) świadczyć to, iż Molly pokazuje paznokciem małżonkowi w „autentycznej powieści społecznej z końca XIX wieku, będącej opowieścią o młodej, ubogiej dziewczynie Ruby, sprzedanej przez własną rodzinę do cyrku" ${ }^{15}$ słowo metempsychoza, którego - jak sprawdziła Mary Power, odkrywczyni egzemplarza tej zaczytanej do cna publikacji - nie ma tu ${ }^{16}$. Cała ta podejrzana procedura nadużywania zaufania do słowa drukowanego, zaufania, które u progu XX stulecia jeszcze żywili czytelnicy, a do nowej definicji kłamstwa jako postprawdy pozostawał wszak wiek z okładem, nie byłaby tak istotna, gdyby nie fakt, że to właśnie pojęcie metempsychozy i pomysłowe ułatwienie sobie przez Molly zapamiętywania tego fenomenu stało się jednym z naczelnych motywów przewodnich dublińskiego eposu. Najpierw tak niewyraźnie pyta męża o to słowo, że ten dopytuje: „mnie tam co?”" mnie tam psy chodzą, zanim nie powiedziałem jej o wędrówce dusz" ${ }^{18}$. Następnie będzie wielokrotnie przypominać sobie tę grę słów: „Pani Marion mnie tam psy chodzą", „metempsychoza (mnie tam psy chodzą)" ${ }^{19}$.

${ }^{12} \mathrm{~W}$ oryginale (Ulysses, 597) czytamy o tym fakcie: „they drank in jocoserious silence Epps's massproduct, the creature cocoa", czego nie udało się przetłumaczyć poprawnie na język polski (Ulisses, 605): „pili w żartobliwie-poważnym milczeniu masowy produkt Eppsa, owo kakao stworzenia”. Otóż słowo „massproduct” jest kalamburem, w którym Joyce zderzył przymiotnik („,masowy”) z rzeczownikiem „msza” („mass”)! Stąd Helmut Bonheim widzi tu „literal communion” („dosłowną Komunię Świętą”), a kakao zastępuje „rytualne wino mszalne”. Vide idem, Joyce's Benefictions (Berkeley and Los Angeles: University of California Press, 1964), 128. Tadeusz Pióro twierdzi, iż źle przełożono też metaforę „the creature cocoa” na „owo kakao stworzenia” (idem, „ "Owo kakao stworzenia»: ku nowym przekładom Ulissesa”, Literatura na Świecie, no. 7-8 (2004): 236).

Uważam, idąc za Bonheimem, że można omawianą przenośnię tłumaczyć choćby tak: „owo zbawienne kakao", gdzie zachowana byłaby dwuznaczność: 1. pożywianie się, 2. kontakt z numinosum; czy w „owo” nie ma aluzji do „,ab ovo”?

${ }^{13}$ Słomczyński niepotrzebnie daje tu dwie duże litery: Ruby: Chluba Areny (James Joyce, Ulisses, 64), gdy czeski thumacz zrywa z angielską konwencją „tytularną" (James Joyce, Odysseus, 55: Ruby, chlouba manéže).

${ }^{14}$ Weldon Thornton, op. cit., 475; Piotr Paziński, Labirynt i drzewo. Studia nad „Ulissesem” Jamesa Joyce’a (Kraków: Wydawnictwo „Austeria”, 2005), 121. Paziński korzysta z danych zawartych w książce Dona Gifforda „Ulysses” Annotated (Berkeley: University of California Press, 1989).

${ }^{15}$ Piotr Paziński, op. cit., 383.

${ }^{16}$ Ibidem, 383.

${ }^{17}$ James Joyce, Ulisses, 63; w oryginale: „Met him what?” (James Joyce, Ulysses, 66); po czesku: „Cože metem?” (James Joyce, Odysseus, 55).

${ }^{18}$ James Joyce, Ulisses, 152; w oryginale: „Met him pikehoses she called it till I told her about the transmigration” (James Joyce, Ulysses, 153); po czesku kalambur brzmi: „hnětem si kozy” (James Joyce, Odysseus, 121).

${ }^{19}$ James Joyce, Ulisses, 267, 615; idem, Ulysses, 268, 607. 


\section{Tomy realne i wirtualne}

Marion Bloom zrezygnowała z przeczytania powieści o Ruby, bo nie była dla niej zbyt pociągająca czy podniecająca: „Nie ma w niej nic pieprznego” (,There's nothing smutty in it”) ${ }^{20}$. Wolałaby już dostać od Blooma następny tom Paula de Kocka, bo „Ma ładne nazwisko” („Nice name he has”) ${ }^{21}$. Stąd posłuszny Poldy u bukinisty wybiera dla niej Stodycze grzechu (Sweets of Sin) ${ }^{22}$. Jest to książka wymyślona przez Joyce'a. Występuje wśród publikacji, o których tytułach lub autorach da się coś konkretnego powiedzieć: 1. Straszliwe odkrycia Marii Monk, 2. Arcydzieła Arystotelesa, 3. Opowiadania z ghetta Leopolda von Sacher-Masocha, 4. Piękne tyranki Jamesa Lovebircha. Pierwszy tom miał dość długi tytuł, który tłumaczył w skrócie, o jakie sensacje chodziło: Awful Disclosures of Maria Monk as Exhibited in a narrative of her [...] residence of five years as a novice, and two years as a black nun, in the Hotel Dieu Nunnery at Montreal $\left(\right.$ New York 1836) ${ }^{23}$. Autorka okazała się oszustką, ale jej rewelacje sprzedano w nakładzie bliskim 250.000 egzemplarzy!

Drugi tom nie ma nic wspólnego z Arystotelesem! Jest to soft pornografia, wydawana od końca XVII wieku. Wydanie londyńskie z roku 1694 przynosi w podtytule istotne informacje: Secrets of Generation displayed in all the parts thereof ${ }^{24}$. Nawiązuje sie do tego dzieła w epizodzie „Woły Heliosa”, rozmawiając - w szpitalu położniczym - o „wszystkich rodzajach ludzkich narodzin, które Arystoteles sklasyfikował w swym arcydziele z chromolitograficznymi ilustracjami" ${ }^{25}$. Taką samą pornografią bywały wówczas utwory Sacher-Masocha. Joyce miał w swojej biblioteczce powieść tego austriackiego literata, przełożoną na włoski: Scene del Ghetto (Milan 1909), co mogło być tłumaczeniem niemieckiego oryginału: Polnische Ghetto-Geschichten (1886) ${ }^{26}$. Lovebirch był twórcą literatury o flagelantach, więc zmyślony tytuł Piękne tyranki jest sadystycznym biegunem masochistycznych powieścideł Sacher-Masocha, znanego głównie z dzieła Wenus $w$ futrze, wspominanego zresztą dwukrotnie w epizodzie „Cyrce”. Joyce wykreował „arcydzieło” podrzędnej literatury

${ }^{20}$ James Joyce, Ulisses, 64; idem, Ulysses, 66.

${ }^{21}$ James Joyce, Ulisses, 64; idem, Ulysses, 66. Po angielsku „kock” to „kogut”, ale i „penis”.

${ }^{22}$ James Joyce, Ulisses, 234; idem, Ulysses, 235.

${ }^{23}$ Weldon Thornton, op. cit., 229. Thumaczenie tytułu: Straszliwe odkrycia Marii Monk ukazane w opowieści o jej pobycie przez pięć lat jako neofitki, a dwa lata jako czarnej zakonnicy w klasztorze żeńskim Hotel Dieu w Montrealu.

${ }^{24}$ Weldon Thornton, ibidem. Tłumaczenie tytułu: Sekrety rozmnażania się dotyczace wszystkich organów ptciowych.

${ }^{25}$ James Joyce, Ulisses, 410. Nawet Molly wspomina ten tom: „otuleni ciepło w łóżeczku jak dzieci w Arcydziele Arystokraty które przyniósł mi kiedyś jakbyśmy nie mieli tego dosyć w prawdziwym życiu" (ibidem, 705).

${ }^{26}$ Weldon Thornton, op. cit., 229. 
pornograficznej (Słodycze grzechu), a w nim trzy częstokroć powracające w Ulissesie obrazy:

[1.] Wszystkie dolarowe banknoty, otrzymywane od męża, wydawała w magazynach na przepiękne suknie i najdroższe fatałaszki. Dla niego! Dla Raoula! [...]

[2.] Jej wargi stopiły się z jego wargami w słodkim całunku rozkoszy, podczas gdy dłonie jego prześlizgiwać się jęły po wypukłych krągłościach wewnątrz jej dezabilu. [...]

[3.] Piękna kobieta odrzuciła swój przybrany sobolami płaszcz, ukazując królewskie ramiona i falujące wdzięki ${ }^{27}$.

Jest to fundament persewerujących w dalszych epizodach motywów. Przykładowo: „Oczy jego przesunęły się. Słodycze grzechu. Słodkie są słodycze. Grzechu”; „Naprzód. Dla Raoula”; „poszedł [...] niegrzeczny Henryk [Bloom - J.P.] z listem do Mady, z grzechu słodyczami z fatałaszkami dla Raoula z mnie tam psy chodzą szedł Poldy przed siebie"; o Molly jako egzotycznej piękności: „To ta południowa krew. Mauretańska. Także kształt, sylwetka. Dłonie prześlizgiwać się jęły po krągłościach”; „perfumować twej żony czarne włosy falujące wdzięki”" 28 . Pełno jest tego, a w końcu i Molly jeszcze zainteresowała się - po północy! - tym erotycznym przebojem: „ciekawa jestem co za książkę mi przyniósł Słodycze Grzechu przez gentlemana światowca pewnie jakiś drugi taki pan de Kock"29. Tak oto powstaje mało zauważana przez krytykę triada cytatów, która generuje następne cytaty - coś na kształt cytowalnej cytadeli cytatologicznej! Joyce kolejny raz okazuje się mistrzem pastiszu i parodii, a ogólniej rzecz ujmując - wielkim stylistą i podglądaczem bądź podrabiaczem wszelakich stylów, a w tym wysokiej, ale i niskiej literatury.

\section{Tomy z różnych półek}

Bloom jest filistrem, gdy książki ocenia według ich gabarytów i kolorów. Tomem największym okazuje się Historia wojny rosyjsko-tureckiej Sir Henry'ego Montague Hoziera, wydana w latach 1877-1879, a najpiękniej ozdobiony jest egzemplarz Dziet Szekspira („,iemnoszkarłatny safian, złoto wytłaczane”) ${ }^{30}$. Akwizytor dobrze sobie radzi w dysputach szekspirologicznych, prowadzonych

${ }^{27}$ James Joyce, Ulisses, 234.

${ }^{28}$ Ibidem, 258, 259, 287, 371-372, 381.

${ }^{29}$ Ibidem, 697.

${ }^{30}$ Ibidem, 639, 637. Ciekawe jest to, że najpierw w tym kosmicznym epizodzie (jak dużo mówi się tu o gwiazdach, także tych, które pojawiły się w roku urodzenia Blooma, Dedalusa i... Szekspira) kolorami-symbolami miały być barwy mleczne i gwieździste, a w końcu nic z tego nie wyszło; vide Michael Groden, „Ulysses” in Progress, Princeton, New Jersey: Princeton University Press, 1977, 176 (,starry, milky”), 193 (,,none”). 
z Dedalusem w szpitalu, w zajeździe i w domowych pieleszach (dużo wie o problemie autorstwa utworów mistrza teatru), ale w potrzebie potrafi także sięgnąć po popularne wybory cytacji poety przełomu XVI i XVII wieku: „W muzyce są czary, powiadał Shakespeare. Cytaty na każdy dzień roku"31. Tenże akwizytor wyzyskuje podręczniki do dokształcania się w wielu dziedzinach (historia, astronomia, religioznawstwo, geografia), a nawet do nabrania ciała i siły: studiując książkę Eugene (sic!) [ma być: Eugen] Sandowa Siła fizyczna i jak ja zdobyć (London 1897), powiększył sobie muskuły: „pierś 28 cali i $291 / 2$ cala, biceps 9 cali i 10 cali, przedramię $8 \frac{1}{2}$ cala i 9 cali, udo 10 cali i 12 cali, łydka 11 cali i 12 cali" 32 .

Ciekawe jest zainteresowanie dublińskiego akwizytora dokonaniami Napoleona. Ba, śledzi nawet raporty z lekarskiej autopsji po śmierci cesarza. Doktor Archibald Arnold miał stwierdzić podobieństwo jego piersi do biustu żeńskiego ${ }^{33}$. Do tego badania nawiązuje Bloom: „Należy wybaczać pomyłki. Nawet wielki Napoleon, gdy dokonywano na nim nagim pomiarów po śmierci...”34. A dla ukrytej uciechy i satysfakcji przechowuje tom nieco podejrzany: „Lockarta Życie Napoleona (brak okładki, uwagi na marginesach, pomniejszające zwycięstwa, wyolbrzymiające klęski bohatera książki)" "35. Filisterstwo Blooma objawia się też w czytaniu sensacji ze świata literatury: głośnym wydarzeniem w Europie, a przede wszystkim w niemieckojęzycznych krajach, była antypolska i antysemicka powieść Gustawa Freytaga Soll und Haben, którą Poldy posiada w oryginale! Rzecz została wydana w roku 1855, a już po 5 latach miała 100 wznowień i przez długie lata była - drugim po Biblii - bestsellerem ${ }^{36}$. Bloom czyta więc prawie wszystko bez wyboru i bezstronnie! Poznawszy Filozofie Talmudu (jest to 13. pozycja w jego katalogu), podczytując tom Hagady, trzymany w szufladzie biurka, sięgając po Myśli wybrane Spinozy (8. tom spisu) czy Utajone życie Chrystusa (19. tom), nie pomija wrogiej mu - jako Żydowi - powieści Freytaga.

${ }^{31}$ James Joyce, Ulisses, 279. O dyskursie ze Stefanem (Bacon contra Szekspir) vide ibidem, 560. W książce Davida Haymana w indeksie pojawia się nawet hasło: Bloom, Leopold, as Shakespeare (idem, „Ulysses”. The Mechanics of Meaning, Madison, Wisc.: The University of Wisconsin Press, 1982, 165).

32 James Joyce, Ulisses, 652.

${ }^{33}$ Weldon Thornton, op. cit., 413.

${ }^{34}$ James Joyce, Ulisses, 514.

${ }^{35}$ Ibidem, 638. Bloom mógł mieć skrót (wydany w roku 1885 lub później, zatytułowany Life of Napoleon Buonaparte) olbrzymiej księgi, którą napisał John Gibson Lockhart pod nagłówkiem The History of Napoleon Buonaparte (1829). Jak widać, Słomczyński popełnił błąd w nazwisku historyka, a czeski tłumacz był staranniejszy!

${ }^{36}$ Weldon Thornton, op. cit., 475. Wedle Gerarda Koziełka „Powstańczy Kraków jest też tłem akcji księgi trzeciej powieści G. Freytaga Winien i ma (Soll und Haben, 1855); zarówno wydarzenia, jak i atmosfera, dalekie są od prawdy historycznej” (Stownik literatury polskiej XIX wieku, ed. Józef Bachórz i Alina Kowalczykowa, Wrocław: Ossolineum, 1991, 611). 
Na półce Blooma, wśród tylu „iskrzących się tytułów” (,scintillating titles”37), mieszczą się także trzy książki pisarzy irlandzkich. Chodzi o poetów Denisa Florence'a McCarthy'ego (1817-1882), Williama Allinghama (1824-1889) i powieściopisarza Williama O'Briena (1852-1928). McCarthy (w Ulissesie - M'Carthy) był autorem 7 książek, ale żadna $\mathrm{z}$ nich nie miała tytułu Poetical Works ${ }^{38}$ : wydano mu Poems (Dublin 1882) oraz - zapewne tuż po śmierci - Poems of Denis F. McCarthy with Life and Notes (Dublin, bez daty). Wedle biografa Joyce'a, Richarda Ellmanna, był to bard niskich lotów: Dedalus (jak i Joyce) nauczał w szkole, mieszczącej się w Dalkey, dzielnicy Dublina, założonej „w Summerfield Lodge, dawnej rezydencji drugorzędnego poety [...] McCarthy'ego, którego nazwisko powtarza się w Finnegans Wake ${ }^{39}$. Skąd wziął się Denis Florence w biblioteczce Blooma? Może jako wspomnienie Dalkey? A może dlatego, iż był to zasłużony tłumacz „hiszpańskiego Szekspira”, czyli Calderona? Przełożył wiele jego dramatów, w tym jakże eufoniczny nagłówek: La Aurora en Copacabana. Może w końcu zadecydował o wszystkim piękny pseudonim poety - Desmond - przewijający się w powieści jako nazwa irlandzkiej prowincji: „hrabia Desmond mógł zawierać traktaty z samym cesarzem Karolem Piątym”; ,irlandzki okręt [...] z najstarszą banderą pływającą, banderą prowincji Desmonda i Thomonda" ${ }^{40}$.

Drugim poetą jest tu William Allingham, autor książki Laurence Bloomfield in Ireland (1864; pisanej w latach 1863-1864 i zawierającej aluzję do powstania styczniowego). George Sampson pisze o nim, że „nie był naprawdę irlandzkim poetą. Literacko spokrewniony był z angielskimi prerafaelitami i nie ujawniał szczególnego upodobania do irlandzkiej myśli i mowy" ${ }^{41}$. Podobnie było z bohaterem jego poematu, który urodził się w Irlandii, ale wychował w Anglii. W wieku 26 lat zwiedził ważniejsze europejskie kraje i wrócił do rodzinnych stron. Gdy nie zrobił kariery politycznej, stał się ugodowcem: „We suffer; powerful England suffers too”; „What can Ireland singly do?”; „Search the world around, / Where are you safer than on Irish ground?" ${ }^{2}$. Tu pewnie Joyce kierował się nie tyle pięknem rymowanych parzyście 10-sylabowych wersów, co podobieństwem

${ }^{37}$ James H. Murphy, „William O’Brien's When We Were Boys: A New Voice from Old Conventions", Irish University Review, no. 2(22) (1992): 298.

${ }^{38}$ James Joyce, Ulysses, 629.

${ }^{39}$ Richard Ellmann, James Joyce, trans. Ewa Krasińska, ed. Zbigniew Lewicki (Kraków - Wrocław: Wydawnictwo Literackie, 1984), 140.

${ }^{40}$ James Joyce, Ulisses, 326.

${ }^{41}$ George Sampson, Historia literatury angielskiej $w$ zarysie. Podręcznik, trans. Piotr Graff, ed. Irena Dobrzycka (Warszawa: Państwowe Wydawnictwo Naukowe, 1966), 974.

${ }^{42}$ William Allingham, Laurence Bloomfield in Ireland. A Modern Poem (London: MacMillan \& Co, 1869), 260, 269 (tłumaczenie cytatów: „Cierpimy, ale potężna Anglia również cierpi”; „Co może uczynić pojedynczo Irlandia?”; „Szukaj po całym świecie, / Ale gdzie znajdziesz bezpieczniejsze miejsce niż w Irlandii?”). 
nazwisk obu bohaterów - głównej postaci „nowoczesnego poematu” i takiejże postaci z jeszcze bardziej nowatorskiej powieści!

Fabuła When We Were Boys (1890) O’Briena dotyczy przygotowań do narodowego powstania w roku 1867, czyli w okresie, gdy autor miał 15 lat. Mamy tu romans, a jednocześnie relację z gorączkowych przygotowań fenian do walki $\mathrm{z}$ angielskim okupantem. Jezuita Stephen J. Brown w swojej książce Ireland in Fiction: A Guide to Irish Novels, Tales, Romances, and Folk-Lore (Dublin 1919) pisze o dziele O'Briena: znakomita powieść, błyszcząca metaforami i epigramami, z dominującym tematem romantycznego uniesienia, entuzjazmu i egzaltacji, związanych z nadchodzącym wybuchem insurekcji ${ }^{43}$. Wśród badaczy toczy się spór o to, czy ten utwór dziennikarza i polityka (członka parlamentu) ma charakter koncyliacyjny, czy też można dostrzec w nim ostrze antykatolickie ${ }^{44}$. O’Brien pojawia się na półce Blooma, bo widać u redaktora gazet irlandzkich intrygującą ewolucję zapatrywań politycznych: od popierania Charlesa S. Parnella do ostrego zwalczania tego przywódcy narodowego!

W konkluzji chcę wyrazić przeświadczenie, iż biblioteka Blooma dopełnia charakterystykę psychologicznych i filozoficznych cech tej postaci. Podobnie jest w Eugeniuszu Onieginie (1833) Aleksandra Puszkina, gdzie Tatiana przegląda bibliotekę swego byłego ideału: autor nie może zdecydować się, czy książki mają ukazać romantyczny, czy też bardziej racjonalny charakter dandysa (stąd większość strof o tomach Oniegina pozostała w brulionach!). Szkoda, że w o rok późniejszym Panu Tadeuszu nie widzimy podobnego opisu bibliotek na Litwie! Można sobie bowiem wyobrazić, iż księgozbiór bywa obrazem mentalności i historii całego kraju. Oto w Oziminie Wacława Berenta - miejscem akcji jest Warszawa w 1904 roku, tak jak w Ulissesie Dublin z tegoż czasu - profesor z Krakowa podziwia wielkopańską bibliotekę w pałacu Niemana:

Obfity księgozbiór gospodarza zasobny był w najrzadsze druki rakowskie, oliwskie, brzeskie, drohomilskie [dobromilskie - J.P.], mohylowskie, pochodzące zgoła ze wszystkich tych kątów i kresów Rzeczypospolitej, gdzie dawniej pracowały tłocznie drukarskie, a dziś kozy się pasą lub żeruje ciemne mrowie ludzkie. [...]

Wyrywając książki z półek na traf, zabłąkał się profesor niebawem w tym lesie. Oto minął rychło pisarzy Wieku Złotego, w tak zwanym Baroku natkną się na pyszne wydawnictwa oliwskie, za czym pociągnięty zewnętrznym luksusem wydawnictw Groelowskich i puławskich, wstąpił myślą w senatorskie koło postaci o posągowym geście i jasnym spojrzeniu wieku Oświecenia - na tę nową falę światowego przypływu, która szczytu swego nie sięgnąwszy runęła w dziejów odmęty, by odwieczną współpracę ducha u warsztatu ludzkości i tradycyjny kontakt z jego po świecie mistrzami przekazać oręża współdziałaniu po Europie ${ }^{45}$.

${ }^{43}$ Vide Weldon Thornton, op. cit., 474.

${ }^{44}$ Vide James H. Murphy, op. cit.

${ }^{45}$ Wacław Berent, Ozimina (Warszawa - Lwów: Nakład Jakuba Mortkowicza, 1911), 167-169. Vide Jerzy Paszek, O bibliofilstwie Berenta. Studia Bibliologiczne, no. 2, ed. Jerzy Paszek (Katowice: Wydawnictwo Uniwersytetu Śląskiego, 1988), 56-69. 


\section{Coda}

Niektórzy historycy literatury uważają, iż Leopold Bloom jest bohaterem na miarę Odysa, Eneasza czy Mojżesza - a inni wprost przeciwnie, widzą w nim ignoranta i zboczeńca ${ }^{46}$. Myślę, że ktoś, kto na początku XX stulecia wskazuje młodszym ludziom do lektury dwa podstawowe dzieła Karola Darwina („Danielowi Magrane i Francisowi Wade [...] zalecał [...] ewolucyjne teorie Charlesa Darwina, wyłożone w Pochodzeniu człowieka i Pochodzeniu gatunków" ${ }^{47}$ ), nie mógł być ignorantem. Zresztą dyskusje z Dedalusem i innymi studentami (epizod „Woły Heliosa"), a także odważna dysputa z nacjonalistą irlandzkim o pseudonimie Obywatel (epizod „Cyklop”), świadczą o przebiegłości tego współczesnego Ulissesa. A był również wielostronnym Sindbadem, bohaterem Baśni z 1001 nocy! Na pytanie, $\mathrm{z}$ kim podczas snu wędrował, pada poetycka, poliptotonowa i poliinstrumentalna (gdy policzyć wirtualne „zawody” Blooma) odpowiedź:

Sinbadem Żeglarzem i Tinbadem Trąbkarzem i Dzinbadem Dziwkarzem i Winbadem Wolarzem i Ninbadem Nudziarzem i Finbadem Figlarzem i Binbadem Bednarzem i Pinbadem Piekarzem i Minbadem Malarzem i Hinbadem Hafciarzem i Rinbadem Rymarzem i Dinbadem Kuglarzem i Vinbadem Zielarzem i Linbadem Stolarzem i Xinbadem Pstryksiarzem ${ }^{48}$.

\section{BLOOM'S LIBRARY}

\section{Su m m a ry}

Leopold Bloom's library contains works of various categories: religious (The Hidden Life of Christ, Philosophy of the Talmud, "an ancient hagadah book"), historical (The Secret History of the Court of Charles II, Lockhart's Life of Napoleon, Hozier's History of the Russo-Turkish War), astronomic (A Handbook of Astronomy, The Story of the Heavens by Sir Robert Ball), geographic (Ellis's Three Trips to Madagascar, Voyages in China by "Viator", In the Track of the Sun), geometric (Short but yet Plain Elements of Geometry written in French by F. Ignat. Pardies), literary (Shakespeare's Works, Denis Florence McCarthy's Poetical Works, When We Were Boys by William O'Brien, The Stark-Munro Letters by A. Conan Doyle, Soll und Haben by Gustav Freytag), philosophical (Thoughts from Spinoza), as well as practical guides and calendars. Most of these works and professional publications are occasionally referred to, as leitmotifs, in the epic of Dublin, yet, most frequently Joyce chooses to quote the romance book he made up, namely, Sweets of Sin! Richard M. Kain claims that there are a few thousands of leitmotifs persevering in Ulisses, which is the unquestionable essence of this encyclopaedic novel.

${ }^{46}$ Vide Edward C. McAleer, „The Ignorance of Mr. Bloom”, in Studies in honor of John C. Hodges and Alwin Thaler, Knoxville, Tenn.: University of Tennessee Press, 1961, 121-129; Clive Hart, „The Sexual Perversions of Leopold Bloom”, in „Ulysses” cinquante ans après, ed. Louis Bonnerot (Paris: Didier, 1974), 131-136; Glenn Timmermans, „Mojżesz i Bloom - nieobrzezani Żydzi”, trans. Katarzyna Bazarnik, in Wokót Jamesa Joyce'a. Szkice monograficzne, ed. Katarzyna Bazarnik i Finn Fordham (Kraków: Universitas, [1998]), 63-76.

${ }^{47}$ James Joyce, Ulisses, 647. Są to tomy z lat 1859 i 1871.

${ }^{48}$ Ibidem, 668. 